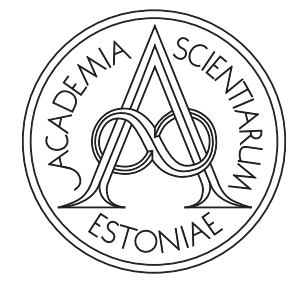

Proceedings of the Estonian Academy of Sciences, $2021,70,4,470-476$

https://doi.org/10.3176/proc.2021.4.14

Available online at www.eap.ee/proceedings

MANUFACTURING ENGINEERING

\title{
Coupling with adjustable torsional stiffness
}

\author{
Kalle Kinnunen*, Sampo Laine, Tuomas Tiainen, Risto Viitala, Alvari Seppänen, \\ Tommaso Turrin, Panu Kiviluoma and Raine Viitala
}

Department of Mechanical Engineering, Aalto University, Sähkomiehentie 4, 02150 Espoo, Finland

Received 5 July 2021, accepted 5 October 2021, available online 8 November 2021

(C) 2021 Authors. This is an Open Access article distributed under the terms and conditions of the Creative Commons AttributionNonCommercial 4.0 International License (http://creativecommons.org/licenses/by-nc/4.0/).

\begin{abstract}
This study presents a novel coupling design with adjustable torsional stiffness. Since the torsional stiffness of the coupling can be adjusted, it can potentially be applied to tune the torsional natural frequencies of rotating systems. The presented coupling design provides clear benefits compared to typical flexible element couplings. For applications with typical flexible element couplings with elastomeric inserts, the torsional stiffness can be adjusted by changing the elastomers. However, this often requires disassembly of the coupling, and the torsional stiffness adjustment has to be performed in large increments. In the presented coupling design, the torsional stiffness can be adjusted without disassembly. The torsional stiffness can be tuned to a wide range of stiffnesses and with arbitrarily small increments. The torsional stiffness of the coupling was determined by analytical calculations, FEM simulations and experimentally. In the experimental tests, the torsional stiffness range of the coupling was measured to be between $8-126 \mathrm{kNm} / \mathrm{rad}$. Experimental measurements agree with the calculated and simulated stiffness values. The coupling design was considered to be successful, since the study confirmed that the torsional stiffness of the coupling can be adjusted to a wide range of different values.
\end{abstract}

Key words: coupling, torsional stiffness, torsional vibrations, adjustable, stiffness, resonance.

\section{INTRODUCTION}

Torsional vibrations are present in almost every rotating system and some machines are inherently prone to torsional vibrations. For example, pumps and combustion engines produce torsional excitations due to their operating principles. Torsional vibrations produce cyclic stresses, which can make the machine elements susceptible to fatigue damage [1]. The vibrations can manifest heavily due to resonance if the excitation frequency of the system coincides with the torsional natural frequencies of the system. Excitation frequencies present in a system can be difficult to predict and problems caused by torsional vibrations can appear unexpectedly [2]. Unexpected vibration problems may cause unscheduled service or machine failures. Adjusting the torsional natural fre-

\footnotetext{
* Corresponding author, kalle.kinnunen@aalto.fi
}

quency of a system can reduce the vibrations by preventing the resonance.

The torsional stiffness of a coupling affects the torsional natural frequencies in rotating systems. It needs to be considered especially in applications where torsional vibration problems are known to occur. However, usually the torsional stiffness of a coupling is not easily adjustable. In commercial flexible element couplings, the adjusting of the torsional stiffness typically requires disassembly of coupling and changing of the flexible inserts. If torsional vibration problems caused by resonance manifest unexpectedly, for example in the first runs of the machine, disassembling the coupling and adjusting the stiffness may require a significant amount of work. In the worst case, large components need to be removed, reassembled and realigned to adjust the torsional stiffness of the coupling. 
In this study, a coupling design with adjustable torsional stiffness is presented. The adjustment of the torsional stiffness is based on changing the effective length of a shaft and cantilever beams in the coupling. Easily adjustable torsional stiffness is beneficial for large machines and for other rotating systems where the torsional properties are difficult to calculate or predict. Various prototypes of couplings and joints with adjustable torsional stiffness similar to the coupling presented in this study have previously been developed [3-10]. These designs use a wide range of different methods to adjust the torsional stiffness such as springs, beams, magnetorheological fluids and elastomers, and pneumatics.

The main goal of this study was to present a novel adjustable stiffness coupling design and to determine the torsional stiffness range and feasibility of the design. The torsional stiffness of the coupling was determined by using analytical calculations, FEM simulations and with experimental measurements. The static stiffness measurements were performed using a lathe as a test bench. The output half coupling was fixed to the tailstock of the lathe. The input half was clamped to the chuck of the lathe to allow only for rotation around the torsional axis. Torque was applied to the input half with torque wrench. The torque and the angular displacement were measured. From the measured torque and the angular displacement, the torsional stiffness of the coupling was calculated. With some modifications and suitable dimensioning, the coupling design could potentially be applied to industrial applications to prevent torsional vibration problems.

\section{COUPLING DESIGN WITH ADJUSTABLE TORSIONAL STIFFNESS}

Figure 1 presents the coupling and the main parts. The coupling consists of input and output halves at its ends, six beams, an adjustable flange and a middle shaft. The shaft of the torque source is attached to the input half of the coupling. Torque is transferred from the input half through the beams to the adjustable flange. The flange transfers the torque to the middle shaft by a spline. The middle shaft is fixed to the output half. The torsional stiffness of the coupling is determined by the effective lengths of the beams and the middle shaft, and they are adjusted by moving the adjustable flange longitudinally. The effective lengths of the beams and the shaft are roughly inverse. Thus, when the beams are at their stiffest position, the shaft stiffness is at its lowest and vice versa. Both the beams and the middle shaft have high stiffness when their effective lengths are low. However, the lowest stiffness of the middle shaft is much higher than the lowest stiffness of the beams, so the highest stiffness is achieved when the adjustable flange is near the input half.

The beams were made of high-strength low-alloy steel. High-strength steel can prevent possible yielding of the beams if the coupling is loaded heavily when the effective length of the beams is high. 3D printed PLA plastic parts were placed between the beams and their grooves to allow for the possibility to easily change the thickness of the beams by $3 \mathrm{D}$ printing of new plastic fitting parts for beams with a different thickness. Moreover, in the adjustable flange the plastic parts allow the flange to slide efficiently when it is moved. The beams are slightly larger than the groove in the plastic parts, so there is no clearance that could cause problems during operation. The beams are attached to the input half with screws and to the output half with sliding connection. The sliding connection allows the beam to move in longitudinal direction but prevents the beam from coming out of the groove.

The cross-sectional profile of the beams has a significant impact on the stiffness of the coupling. The beams could be designed to be tapered or wider at certain position to alter the torsional properties of the coupling. In the

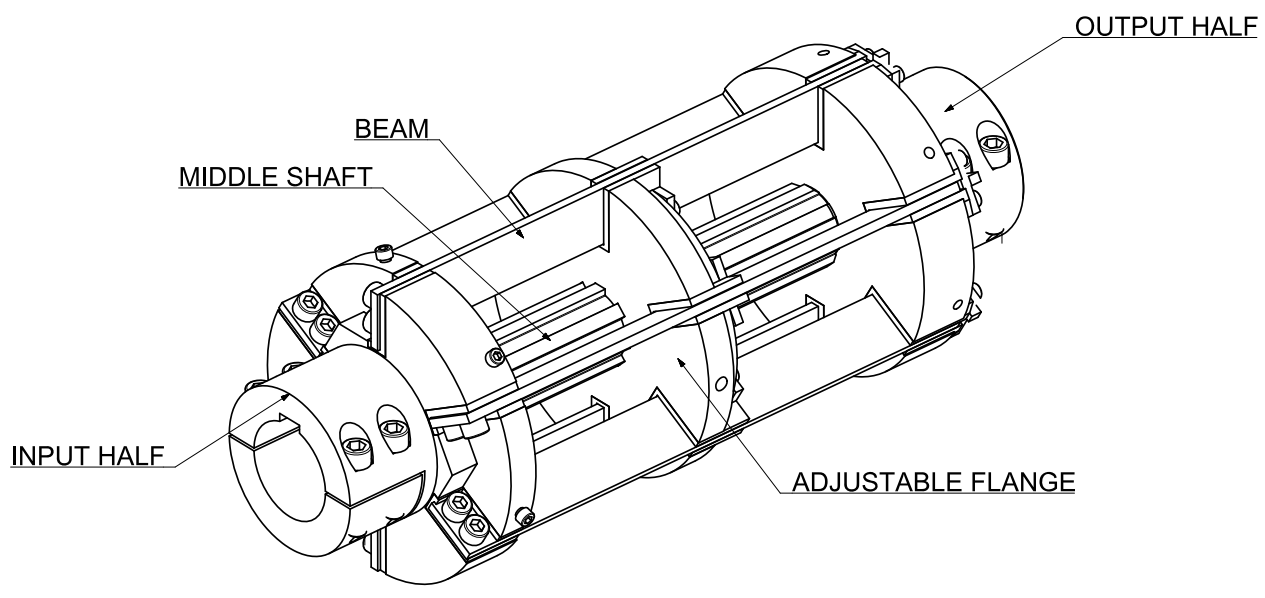

Fig. 1. The main parts of the coupling. 
presented design, the shape of the beams is rectangular to test the shape that facilitates straightforward modelling and analysis.

\section{METHODS}

The torsional stiffness of the coupling design in different operation points, i.e., effective lengths of the beams and the shaft, was determined by three methods: analytical calculations, FEM simulations and experimental measurements.

\subsection{Analytical calculations}

The analytical calculations for determining the torsional stiffness of the proposed coupling design were performed by calculating the stiffness contributions of the beams and the middle shaft. The splined middle shaft was simplified to a plain round shaft with a suitable thickness, i.e., to the smallest diameter at the bottom of the splines. The total torsional stiffness of the coupling was calculated by considering the beams and the shaft as torsional springs connected in series. The geometrical and material parameters are presented in Table 1 and the dimensions used in the calculations are presented in Fig. 2.

When torque is applied to the coupling, the beams are subjected to bending and twisting. The stiffness of the beams was calculated by combining the torsional and lateral bending stiffness properties according to the principle of superposition. The formula for torsional springs in series was used in the calculation. The beam stiffness was multiplied by 6 , which is the number of beams in the coupling.

When torque is applied to the coupling, the beams are subjected to bending and twisting. The stiffness of the beams was calculated by combining the stiffness caused by both types of displacement. The beam stiffness due to lateral bending $k_{\text {bending }}$ was calculated using the fundamental torsional stiffness formula

$$
k_{\text {bending }}=\frac{F \cdot r}{\theta},
$$

where $F \cdot r$ is the torque and $\theta$ denotes the angle of twist. The angle of twist was calculated by applying the cantilever beam deflection with rigid support and a point

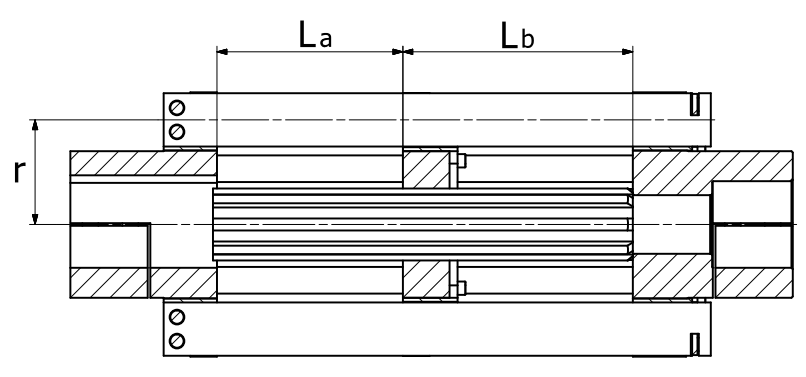

Fig. 2. Dimensions used in the calculations.

force at the free end. The angle of twist in the lateral beam deflection can be defined as

$$
\theta=\frac{\delta}{r}
$$

where $\delta$ is deflection of the beam. This deflection distance for the given boundary conditions is given by

$$
\delta=\frac{F L_{a}^{3}}{3 E I},
$$

where $L_{a}$ is the effective length of the beams and $\mathrm{E}$ represents the Young's modulus of the beams. $I$ is the second moment of inertia defined as

$$
I=\frac{h b^{3}}{12},
$$

where $h$ refers to the height and $b$ denotes the thickness of the beam. Thus, the total stiffness against bending is

$$
k_{\text {bending }}=\frac{3 E I r^{2}}{L_{a}^{3}} .
$$

The beams also twist torsionally when the torque is applied to the coupling. The beam stiffness against torsional twisting is calculated with the equation

$$
k_{\text {twisting }}=\frac{G J_{a}}{L_{a}},
$$

where $J_{a}$ represents the torsion constant for the rectangular cross-section of the beam. $J_{a}$ is defined as

$$
J_{a}=\beta h b^{3}
$$

where $\beta$ is 0.3 , which is defined by the height to width ratio of the cross-section [11]. The stiffness of the middle

Table 1. Geometrical and material parameters used in the analytical calculations

\begin{tabular}{c|c|c|c|c|c|c}
\hline $\begin{array}{c}\text { Parameter } \\
\text { \& unit }\end{array}$ & $\begin{array}{c}\text { Radius } \\
\mathrm{r}[\mathrm{mm}]\end{array}$ & $\begin{array}{c}\text { Young's modulus } \\
\mathrm{E}[\mathrm{GPa}]\end{array}$ & $\begin{array}{c}\text { Shear modulus } \\
\mathrm{G}[\mathrm{GPa}]\end{array}$ & $\begin{array}{c}\text { Beam thickness } \\
\mathrm{b}[\mathrm{mm}]\end{array}$ & $\begin{array}{c}\text { Beam height } \\
\mathrm{h}[\mathrm{mm}]\end{array}$ & $\begin{array}{c}\text { Shaft diameter } \\
\mathrm{d}[\mathrm{mm}]\end{array}$ \\
\hline Value & 78.5 & 209 & 78 & 6 & 40 & 46
\end{tabular}


shaft $k_{s}$ was defined in accordance with the torsional rigidity definition. For simplicity, the splined shaft is treated as a circular shaft in the calculations.

$$
k_{\text {shaft }}=\frac{G J_{p}}{L_{b}},
$$

where $L_{b}$ is the effective length of the middle shaft. $J_{p}$ denotes the torsion constant for circular cross-section, which is defined as

$$
J_{p}=\frac{\pi d^{4}}{32} .
$$

The total beam stiffness is multiplied by 6 , which is the number of beams in the coupling. Finally, the resulting analytical expression for the total coupling stiffness with the defined stiffness parameters is

$$
k=\left(\frac{1}{6\left(k_{\text {bending }}+k_{\text {twisting }}\right)}+\frac{1}{k_{\text {shaft }}}\right)^{-1} .
$$

\subsection{Simulated torsional stiffness}

The torsional stiffness was also determined by FEM (Finite Element Method) simulations. The simulations were performed using Siemens NX with static solver. Before the simulations, the 3D-model of the coupling was pre-processed to simplify the simulation. Excess parts and detailed geometry such as fillets, screws and the spline tooth were removed. The coupling was meshed with tetrahedral elements. The element size was $3 \mathrm{~mm}$ for the beams and the plastic parts. Larger $6 \mathrm{~mm}$ mesh was used in all other parts. The boundary conditions are presented in Fig. 3. The bore surface of the output half was fixed with all 6 degrees of freedom constrained. A torque load was exerted on the bore surface of the input half.

The output half, the middle shaft and the adjustable flange were rigidly connected. The plastic parts between the beams and the grooves were also considered to be rigidly connected to their grooves. The beams were rigidly connected to the plastic parts from the perimeter of the screws in the input half side. Non-linear contact was applied between other areas where the beams and the plastic parts are in contact. Since the contacts do not provide boundary conditions to the simulation, springs with negligible stiffness were added to the output ends of the beams. The springs act as a boundary condition for the beams and to the input half of the coupling.

\subsection{Static torsional stiffness measurement}

The coupling was tested experimentally with the static torsional stiffness test. The coupling was fixed except for the rotation of the input half. Torque was applied to the input half and the angular displacement was measured. From the torque and angular displacement, the torsional stiffness was calculated. The goal of this test was to validate the coupling design and to determine the torsional stiffness range of the coupling.

A lathe was used as a test bed for the torsional stiffness test. The test setup is presented in Fig. 4. The coupling was mounted between the tailstock and the lathe chuck. The output half of the coupling was fixed with the tailstock. A special tool was made to properly mount the output half to the tailstock. The input half of the coupling was clamped to the lathe chuck, which allowed only rotation around the torsional axis of the coupling. Thus, the test bed fixed every degree of freedom in the output half. The input half had one degree of freedom that was around the torsional axis of the coupling.

A varying torque was applied to the input half of the coupling using a digital torque wrench. The torque wrench was clamped to the centre bore of the input half. Weights were used to apply a constant force to the free end of the coupling. The weights were hung from the handle of the torque wrench and the amount of torque applied to the input half was thus acquired.

The applied torque caused an angular displacement in the input half. The angular displacement of the input half

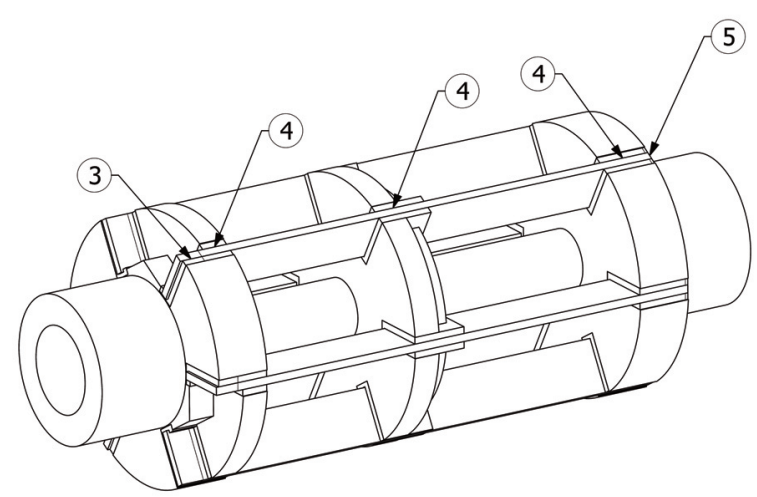

Fig. 3. Forces and boundary conditions in the simplified coupling. 1. Torque load. 2. Fixed constraint. 3. Rigid connection. 4. Non-linear contact. 5. Springs with small stiffness. 


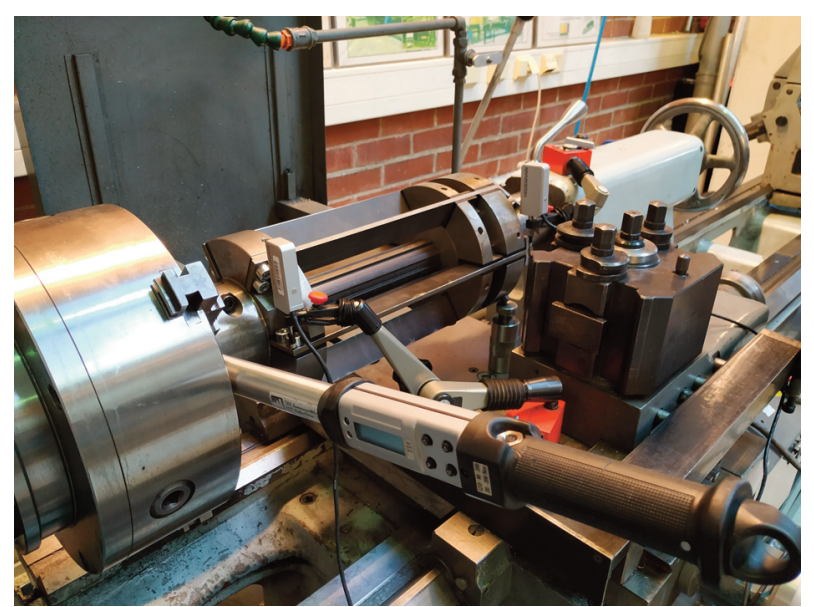

Fig. 4. The coupling in the test bench. The input half is attached to the lathe chuck, which allows rotation in torsional direction. The output half is fixed by attaching it to the lathe tailstock. Two displacement sensors are mounted to measure the displacement of the input end and to ensure that the fixed output end does not rotate. The torque is applied by placing weights to the torque wrench.

was measured by a Heidenhain MT-12 linear displacement sensor. Another similar displacement sensor was mounted to the fixed output half to confirm that it does not rotate or move during the measurements.

The sensors were attached to a dial indicator stand. To measure the angular displacement in the input half, the spindle of the sensor was set against the surface of a beam in the input half of the coupling. The spindle of the sensor was set as perpendicular as possible against the measured surface to prevent cosine error. As the chuck rotated, the measured surface moved the spindle of the displacement sensor. Since the sensor measures only linear displacement, it was converted to angular displacement by dividing the linear displacement with the distance from the axis of rotation to the point of measurement. Measuring the angular displacement indirectly by this method produces an error, since the point that is measured is moving in an arc and not linearly. However, the measured angular displacements were small, so the effect of the error was considered to be negligible.

Next, the measurement procedure is presented.

1. The adjustable flange was moved as close as possible to the input half, which is the position with the highest torsional stiffness.

2. Torque was applied by adding the weight on the torque wrench.

3. The torque and the angular displacement were measured. After the measurements, the weights were removed.

4. The torque and displacement were measured a total of 5 times at the current adjustable flange position and the results were averaged to derive a value of the torsional stiffness.

5. The adjustable flange was moved.

6. Steps $2-5$ were repeated until the whole stiffness range of the coupling was measured.

\section{RESULTS}

The static torsional stiffness of the coupling was determined by analytical calculations, FEM simulations and practical experiments. The results were obtained for the whole range of possible adjustable flange positions. The range was $0-260 \mathrm{~mm}$ measured from the input half. The comparison of the determined torsional stiffness can be seen as function of the adjustable flange position in Fig. 5. Only moderate deviations can be noticed from the determined stiffness curves when they are compared to each other. The simulated and measured stiffness have a very similar type of curve, which suggests that the FEM simulation corresponds to the actual coupling with good accuracy.

\section{DISCUSSION}

When compared to the other curves, the analytically calculated torsional stiffness curve has a differing shape with a distinct peak (Fig. 6a). The shape of the stiffness curve is caused by the interaction between the beam stiffness and the shaft stiffness. When the adjustable flange position is 0 , the effective length of the beams is at its shortest and the effective length of the shaft is at its longest. The short effective length of the beams causes them to have really high stiffness compared to the shaft.

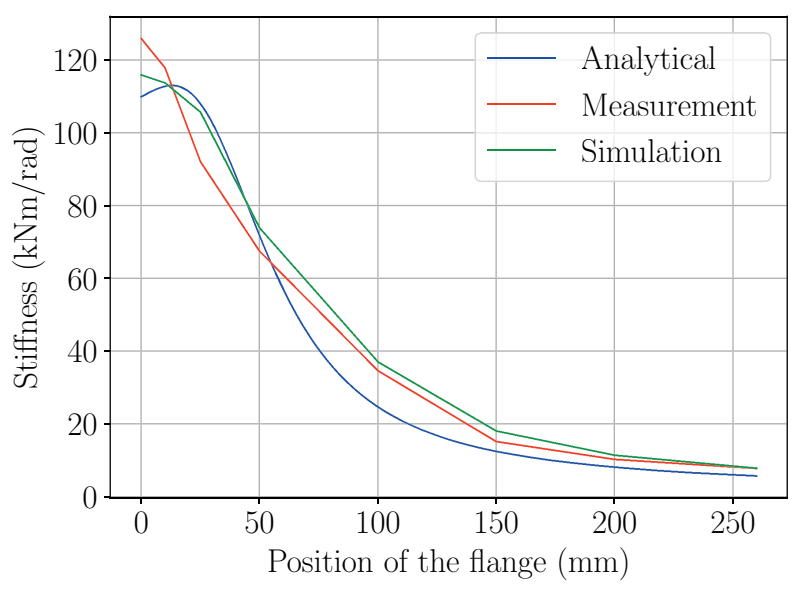

Fig. 5. Torsional stiffness curves from analytical calculations, FEM simulations and practical experiment. The stiffness values are plotted as a function of adjustable flange position. 
(a)

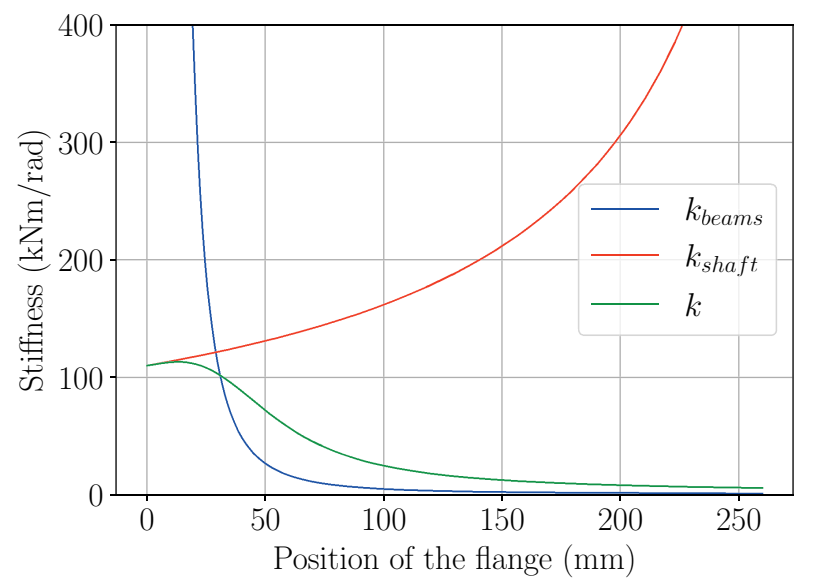

Graph of the shaft stiffness, stiffness of the beams, and stiffness of the coupling. It presents how the stiffness of the shaft and the beams affect the stiffness of the coupling. (b)

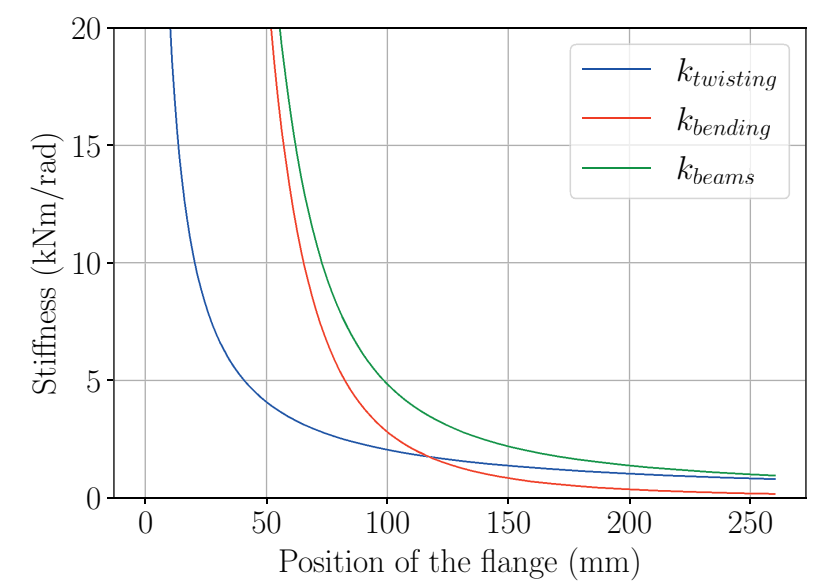

Graph of the stiffness of the beams divided into stiffness against bending and against twisting. The graph demonstrates how the total stiffness of the beams is formed.

Fig. 6. Graphs demonstrating the formation of total torsional stiffness of the coupling.

Since the beams and the shaft are in series, with low flange position, the stiffness of the coupling is determined almost fully by the stiffness of the shaft. As the flange position is increased, the stiffness of the beams starts to decrease rapidly as their effective length increases. When the flange position is at around $13 \mathrm{~mm}$, the stiffness of the beams has decreased sufficiently, so the total stiffness of the coupling peaks and starts to decrease. The stiffness of the beams decreases rapidly until the flange position reaches around $70 \mathrm{~mm}$. The rapid decrease of the beam stiffness reduces the total stiffness of the coupling substantially. After the flange position has increased over $100 \mathrm{~mm}$, the beam stiffness has decreased sufficiently, so that it determines almost fully the total torsional stiffness of the coupling.

The behaviour of the beams can be analysed in depth by dividing the beam stiffness to its components (Fig. 6b). As torque is applied to the coupling, the beams bend and twist. The effect of bending stiffness and twisting stiffness were calculated and the total beam stiffness is their sum. Both stiffness values are high when the flange position is low. However, the bending stiffness is much higher and decreases more slowly than the twisting stiffness, which causes the bending stiffness to determine the total beam stiffness at low flange positions. At higher flange positions the bending stiffness decreases to very low values while the twisting stiffness stays higher. Thus, at higher flange positions the total beam stiffness is mostly determined by the twisting stiffness of the beams.

Potential further research would be to test the dynamic properties of the coupling. The coupling could be installed to a rotating drivetrain and the changes in natural frequencies of the system observed when the stiffness is modified. This would confirm that the coupling design can be used for reducing resonance induced torsional vibrations.

In the current design, the stiffness can be adjusted manually but the stiffness adjusting mechanism could possibly be automated with a servo motor and linear guides. A servo motor would allow automated control of the torsional natural frequency of the rotating system. Thus, the system could be further applied to automatically reduce torsional vibrations by adjusting the torsional stiffness of the coupling.

\section{CONCLUSIONS}

In this study, a coupling with adjustable torsional stiffness has been presented. The torsional stiffness is adjusted by changing the effective length of rectangular beams in the coupling. The torsional stiffness of the coupling was determined by analytical calculations, FEM simulations and experimental measurement. The measured stiffness of the coupling corresponds well with the analytical calculations and FEM simulations. The results of the experiment have validated the coupling design as the torsional stiffness of the coupling was adjusted successfully to a wide range of stiffness values.

\section{ACKNOWLEDGEMENTS}

The publication costs of this article were covered by the Estonian Academy of Sciences and Tallinn University of Technology. 


\section{REFERENCES}

1. Eshleman, R. Torsional vibration of machine systems. In Proceedings of the 6th Turbomachinery Symposium, Texas A\&M University, Texas. 1977, 13-22.

2. Corbo, M. and Malanoski, S. Practical design against torsional vibration. In Proceedings of the 25th Turbomachinery Symposium, Texas A\&M, Texas. 1996, 189-222.

3. Urbanský, M., Kaššay, P. and Vojtková, J. New design solutions of tangential pneumatic torsional vibration tuners. Sci. J. Sil. Univ. Technol. Series Transp., 2019, 103, 183-191.

4. Lee, K.-H., Park, J.-E. and Kim, Y.-K. Design of a stiffness variable flexible coupling using magnetorheological elastomer for torsional vibration reduction. J. Intell. Mater. Syst. Struct., 2019, 30(15), 2212-2221. https://doi.org/ $10.1177 / 1045389$ X19862378

5. Wolf, S. and Hirzinger, G. A new variable stiffness design: Matching requirements of the next robot generation. In Proceedings of the 2008 IEEE Internationl Conference on Robotics and Automation, Pasadena, CA, USA, May 19-23, 2008. IEEE, 1741-1746.
6. Zheng, Y., Zhang, X., Luo, Y., Zhang, Y. and Xie, S. Analytical study of a quasi-zero stiffness coupling using a torsion magnetic spring with negative stiffness. Mech. Syst. Signal Process., 2018, 100, 135-151. https://doi.org/10.1016/ j.ymssp.2017.07.028

7. Choi, J., Hong, S., Lee, W., Kang, S. and Kim, M. A robot joint with variable stiffness using leaf springs. IEEE Trans. Rob., 2011, 27(2), 229-238. https://doi.org/10.1109/TRO. 2010.2100450

8. Li, Z., Chen, W. and Bai, S. A novel reconfigurable revolute joint with adjustable stiffness. In Proceedings of the 2019 International Conference on Robotics and Automation (ICRA), Montreal, QC, Canada, May 20-24, 2019. IEEE, 8388-8393.

9. Gradu, M. and Schlernitzauer, T. L. Stabilizer bar with variable torsional stiffness. Patent US7207574B2, 24 April 2007.

10. Post, R. F. Magnetic bearing element with adjustable stiffness. Patent US8581463B2, 12 November 2013.

11. Ugural, A. C. and Fenster, S. K. Advanced Strength and Applied Elasticity. Pearson Education, London, 2003.

\section{Reguleeritava väändejäikusega sidur}

\section{Kalle Kinnunen, Sampo Laine, Tuomas Tiainen, Risto Viitala, Alvari Seppänen, Tommaso Turrin, Panu Kiviluoma ja Raine Viitala}

Antud uuringus on kirjeldatud uudset sidurit, millel on reguleeritav väändejäikus. Kuna siduri väändejäikust saab reguleerida, saab seda kasutada pöörlevate süsteemide väändesageduste häälestamiseks. Tavalisi paindlike elementidega sidureid reguleeritakse elastomeride vahetamisega. See nõuab sageli siduri lahtivõtmist ja väändejäikuse reguleerimine toimub suurte sammudega. Väljapakutud siduril saab väändejäikust reguleerida ilma seda lahti võtmata. Väändejäikust saab reguleerida laias vahemikus ja väikeste sammude kaupa. Siduri väändejäikus määrati analüütiliste arvutuste, FEMsimulatsioon abil ja eksperimentaalselt. Eksperimentaalsed mõõtmised olid kooskõlas arvutatud ja simuleeritud väärtustega. 